|| ISSN(online): 2589-8698 || ISSN(print): 2589-868X ||

International Journal of Medical and Biomedical Studies

Available Online at www.ijmbs.info

PubMed (National Library of Medicine ID: 101738825)

Index Copernicus Value 2018: 75.71

Volume 3, Issue 4; April: 2019; Page No. 117-121

\title{
A COMPARATIVE STUDY OF OUTCOMES IN MANAGEMENT OF BREAST ABSCESS BY ULTRASOUND GUIDED NEEDLE ASPIRATION AGAINST INCISION AND DRAINAGE
}

\author{
Prabhu Dayal $^{1}$, Mohan Lal ${ }^{2}$ \\ 1,2 MS General Surgery \\ ${ }^{1,2}$ Assistant Professor, Department of General Surgery, Govt. Medical College, Pali, Rajasthan
}

Article Info: Received 11 March 2019; Accepted 15 April. 2019

Cite this article as: Dayal, P., \& Lal, M. (2019). A COMPARATIVE STUDY OF OUTCOMES IN MANAGEMENT OF BREAST ABSCESS BY ULTRASOUND GUIDED NEEDLE ASPIRATION AGAINST INCISION AND DRAINAGE. International Journal of Medical and Biomedical Studies, 3(4).

DOI: https://doi.org/10.32553/ijmbs.v3i4.201

Address for Correspondence: Mohan lal, Assistant Professor, Department of General Surgery, Govt. Medical College, Pali, Rajasthan

Conflict of interest: No conflict of interest.

\begin{abstract}
Background: Breast abscess is a common cause of morbidity in women. While they are less common in developed countries as a result of improved maternal hygiene, nutrition, standard of living and early administration of antibiotics, breast abscess remain a problem among women in developing countries.

Methods: Hospital based prospective randomized controlled trial conducted on 100 patients. 50 of them were randomized in the aspiration group and other 50 were treated by incision and drainage. All statistical analysis was done in Epi-info statistical software.

Results: In our study, patients in the needle aspiration group had lesser pain as compared to the patients of the incision and drainage group. Average pain score (on visual analogue scale) on day three of patients in the needle aspiration group was 4.22 as compared to 5.72 in the incision and drainage group. On day seven the pain score was 1.73 in the aspiration group and 3.89 in the incision and drainage group. By day fourteen almost all patients (94.00\%) of needle aspiration group were pain free and the average pain score in the incision and drainage group was 2.0.Using the chi square test, a $\mathrm{p}$ value of 0.0005 was obtained suggesting a statistically significant difference.
\end{abstract}

Conclusion: Wherever the facility of ultrasound is available, serial percutaneous needle aspiration may be tried as a first line of therapy.

Keywords: Needle aspiration, Incision and drainage, Breast abscess.

\section{INTRODUCTION:}

Breast abscess is a common cause of morbidity in women. While they are less common in developed countries as a result of improved maternal hygiene, nutrition, standard of living and early administration of antibiotics, breast abscess remain a problem among women in developing countries. The most commonly implicated organism is Staphylococcus aureus ${ }^{1}$.

Lactational breast abscess occurring during breast feeding is the result of Staphylococcus infection, affecting $0.4-11 \%$ of lactating females ${ }^{2}$. Such abscesses tend to occur at the commencement of breast feeding when an inexperienced mother developed cracked 
nipples. They also occur at weaning when engorgement results from incomplete drainage of breast milk.

Non-lactational breast abscesses are entirely different from those occurring during breast feeding. The true incidence of this condition in non-lactating females is not knows and is estimated to be $1-33 \%^{3}$. They occur in the periareolar tissues, frequently recur, and infecting organisms are a mixture of Bacteroides, anaerobic streptococci, and enterococci. Such non-lactational breast abscess is a manifestation of duct ectasia/periductal mastitis and is usually seen in the age group 30-60 years.

High-Resolution real-time sonography is a unique means of diagnosing and evaluating the extent, site, size and internal characteristics of breast abscesses. Whereas diagnosis has never been a problem, increased cosmetic concern due to changing social values has caught treating physician in a great dilemma. Traditional treatment of breast abscess is by surgical incision and drainage. Treating breast abscesses in lactating women by aspiration is not new'.lmaging guided percutaneous needle aspiration of purulent collections is a known alternative to standard treatment which has become more popular as it is less invasive, cosmetically better and can be managed entirely on outpatient basis as compared to incision and drainage ${ }^{2}$.

The present study tries to compare the two treatment modalities ultrasound guided needle aspiration and incision and drainage and assess their outcome in patients with breast abscess.

\section{MATERIALS AND METHODS}

\section{STUDY DESIGN:}

This was a hospital based prospective randomized controlled trial.

\section{SAMPLE SIZE:}

100 patients were included in the study. 50 of them were randomized in the aspiration group and other 50 were treated by incision and drainage.

\section{INCLUSION CRITERIA:}

All women above 18 years of age and below 45 years of age

\section{EXCLUSION CRITERIA:}

1. Patients with recurrent abscesses.

2. Breast abscess with signs of impending rupture.

3. Breast abscess with necrotic skin overlying the abscess

4. Breast abscess already draining

\section{METHODOLOGY}

Clinical diagnosis was made based on the presence of a fluctuant tender breast swelling. Patients were then subjected to USG scan (high frequency linear transducer of $7.5 \mathrm{MHZ}$ ) in radiology department. The diagnosis was confirmed sonographically by the presence of a thick-walled echo complex mass, predominantly cystic with internal echoes and septations.

Patients were then randomly divided into each group by computer generated randomization table. A written informed consent was taken from all patients included in the study.

\section{All patients were randomly divided into two groups: -}

Group 1: ultrasound guided needle aspiration

Group 2: incision and drainage of breast abscess

Complete history was taken and general physical examination was done.

Routine blood investigations like hemogram, renal function tests and coagulation profile (Bleeding time, clotting time, Prothrombin time), random blood sugar were done. A primary ultrasonography of the breast was done at time of admission for abscess size, location and number.

\section{Follow Up}

The patients were follow up on days $3,7,14,21$ post intervention and thereafter for three months on a monthly basis.

\section{Data Analysis}


To collect required information from eligible patients a pre-structured pre-tested Proforma will be used. For data analysis Microsoft excel and statistical software SPSS will be used and data will be analyzed with the help of frequencies, figures, proportions, measures of central tendency, appropriate statistical test.

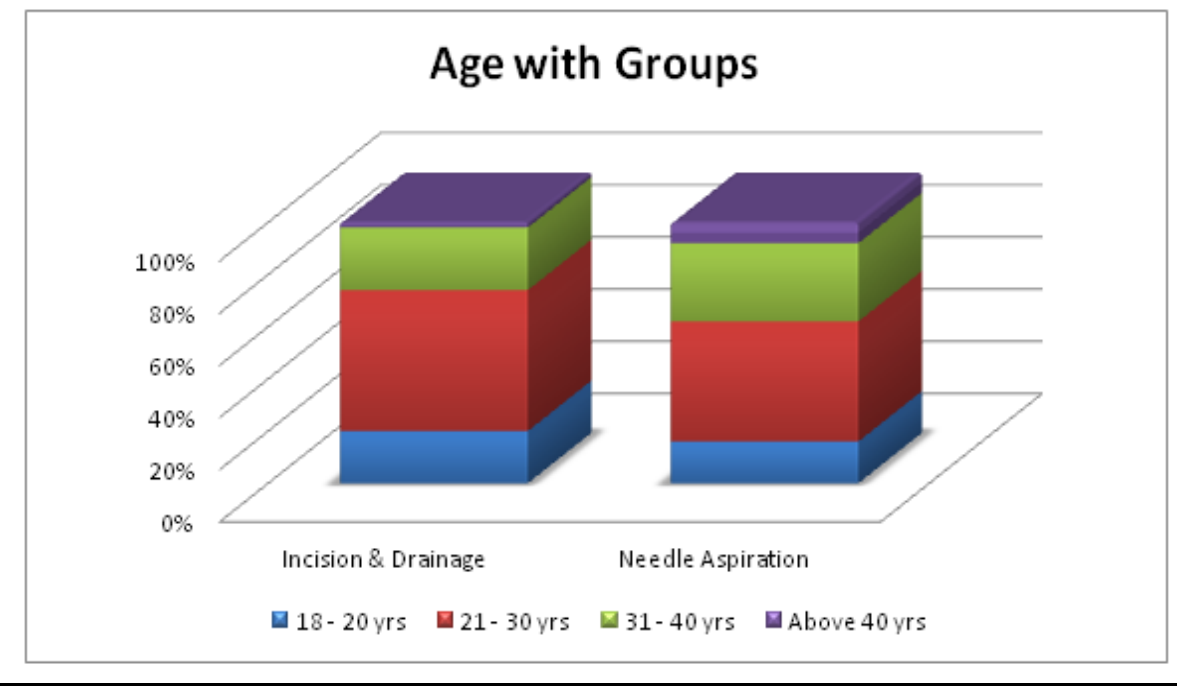

The mean age of patients in our study was 26.54 years. The mean age in incision and drainage group was 26.20 years, and in needle aspiration group, it was 28.20 years. The difference in age group between the 2 groups was statistically Insignificant. ( $p$-value>0.05)

Table 1: Lactational status

\begin{tabular}{|l|l|l|l|l|}
\hline \multicolumn{2}{|c|}{} & \multicolumn{2}{|l|}{ Groups } & \\
\cline { 3 - 5 } \multicolumn{2}{c|}{} & I \& D & NA & Total \\
\hline \multirow{2}{*}{$\begin{array}{l}\text { LACTATIONAL } \\
\text { STATUS }\end{array}$} & NO & 14 & 22 & 36 \\
\cline { 2 - 5 } & YES & 36 & 28 & 64 \\
\hline Total & 50 & 50 & 100 \\
\hline
\end{tabular}

In our study, overall, out of 100 patients, 64(64\%) were lactating and $36(36 \%)$ were non-lactating. In I\&D group 36 patients (72\%) were lactating and 14 patients (28\%) were non-lactating. In needle aspiration group, 28 patients (56\%) were lactating and 22 patients (44\%) were non-lactating. The difference in lactational status between 2 groups was statistically Insignificant.

Table 2: Duration of hospital stay:

\begin{tabular}{|l|l|l|l|l|}
\hline \multicolumn{2}{|c|}{} & \multicolumn{2}{|l|}{ Groups } & \multirow{2}{*}{ Total } \\
\cline { 3 - 5 } \multicolumn{2}{c|}{} & I \& & NA & \\
\hline \multirow{3}{*}{$\begin{array}{l}\text { DURATION OF } \\
\text { HOSPITAL STAY } \\
\text { (DAYS) }\end{array}$} & 1 & 0 & 3 & 3 \\
\cline { 2 - 5 } & 2 & 13 & 27 & 40 \\
\cline { 2 - 5 } & 4 & 23 & 13 & 36 \\
\cline { 2 - 5 } & 5 & 3 & 7 & 18 \\
\hline Total & 50 & 50 & 3 \\
\hline
\end{tabular}


In our study, out of 50 patients in needle aspiration group, the duration of hospital stay was 1 day in 3 patient (6\%), 2 days in 27 patients (54\%), 3 days in 13 patients (26\%), 4 days in 7 patients (14\%). Out of 50 patients in I\&D group, the duration of hospital stay was 2 days in 13 patients (26\%), 3 days in 23 patients (46\%), 4 days in 11 patients (22\%) and 5 days in 3 patients (6\%). This difference in duration of hospital stay between 2 groups was statistically significant.

Table 5: Average pain score

\begin{tabular}{|l|l|l|}
\hline & \multicolumn{2}{|l|}{ Average pain score (10) } \\
\hline Day & Needle aspiration Group & Incision and drainage group \\
\hline 3 & $4.22 \pm 2.82$ & $5.72 \pm 1.82$ \\
\hline 7 & $1.73 \pm 2.87$ & $3.89 \pm 2.12$ \\
\hline 14 & $0.25 \pm 1.65$ & $2 \pm 2.45$ \\
\hline 21 & 0 & 0 \\
\hline 30 & 0 & 0 \\
\hline 60 & 0 & 0 \\
\hline 90 & 0 & 0 \\
\hline
\end{tabular}

In our study, patients in the needle aspiration group had lesser pain as compared to the patients of the incision and drainage group. Average pain score (on visual analogue scale) on day three of patients in the needle aspiration group was 4.22 as compared to 5.72 in the incision and drainage group. On day seven the pain score was 1.73 in the aspiration group and 3.89 in the incision and drainage group. By day fourteen almost all patients $(94.00 \%)$ of needle aspiration group were pain free and the average pain score in the incision and drainage group was 2.0 .

\section{DISCUSSION}

The breast is one of the sex organs of a female, in case of breast disease care should be taken to insure that its beauty is minimally compromised in order to preserve its value and function. Despite of breast abscess becoming less in developed countries due to improved maternal hygiene, nutrition, standard of living and early use of antibiotics, breast abscess remain a problem among women in developing countries ${ }^{4}$. Treatment of breast abscess traditionally has been incision and drainage however this has been found to be associated with possible unsatisfactory cosmetic outcome, difficult in breast feeding and needs general anesthesia, prolonged healing time, and regular dressing ${ }^{5}$. Repeated aspiration with or without ultrasound guidance has been found to be another treatment option for breast abscess and this has been reported to be associated with less recurrence, excellent cosmetic result and has less costs ${ }^{6-8}$

It was noted that $56 \%$ of the females in the needle aspiration group and $72 \%$ of patients in the incision and drainage group were lactational suggested that stasis of milk and carrier state of the infant plays a key role in the development of breast abscess. This is comparable with the finding of Singh et $\mathrm{al}^{9}$ where out of fifty patients $62 \%$ were lactational and $38 \%$ were non lactational. However, in a study done by Elagili et $\mathrm{al}^{10} 53.3 \%$ of patient were seen to be non lactational and $\mathbf{4 6 . 7 \%}$ were lactational. This fact may be explained by better maintenance of maternal hygiene.

In our study, patients in the needle aspiration group had lesser pain as compared to the 
patients of the incision and drainage group. Average pain score (on visual analogue scale) on day three of patients in the needle aspiration group was 4.22 as compared to 5.72 in the incision and drainage group. On day seven the pain score was 1.73 in the aspiration group and 3.89 in the incision and drainage group. By day fourteen almost all patients $(94.00 \%)$ of needle aspiration group were pain free and the average pain score in the incision and drainage group was 2.0.Using the chi square test, a $p$ value of 0.0005 was obtained suggesting a statistically significant difference. Hence it can be derived that incision and drainage is a more painful procedure as compared to needle aspiration. The delayed persistence of pain can be associated to the open wound in patients undergoing incision and drainage which is not there in cases of needle aspiration.

All patients included in the study were admitted in the hospital for a period ranging from 1-4 days. Average duration of hospital stay in needle aspiration group was 3.08 while in needle aspiration group, it was 2.48 . The difference was found to be statistically significant with a $p$-value of 0.006 . In the study conducted by Chandika et al all patients that were treated by needle aspiration did not require admission whereas those treated by incision and drainage were admitted for a variable period of two to five days. $^{11}$

\section{CONCLUSION}

In conclusion it can be said that whenever and wherever the facility of ultrasound is available, serial percutaneous needle aspiration may be tried as a first line of therapy.

\section{REFERENCES}

1. Dabbas N, Chand M, Pallett A, Royle GT, Sainsbury R. Have the organism that cause Breast Abscess Changed with time?Implication for appropriate used in primary and secondary care. The Breast Journal 2010; 16(4):412-5.
2. Marchant DJ. Inflammatory of the breast. Obstetrics and Gynaecology clinics of North America 2002 Mar; 29(1):89-102.

3. Kataria K, Srivastava A, Dhar A. Management of lactational mastitis and breast abscesses: Review of current knowledge and practice. Indian Journal of Surgery 2013 Dec;75 (6):430-5.

4. Thomsen AC, Hansen KB, Moller BT. Leucocyte count and microbiological cultivation in the diagnosis of puerperal mastitis. AmJ Obst Gynec 1983 Aug 15;146 (8):938-41.

5. Haagensen CD. Disease of the Breast. $3^{\text {rd }}$ ed. Philadelphia: WB Saunders; 1986:357-9.

6. Efem SE. Breast abscesses in nigerian women: lactational vs non-lactational women. Journal of Royal College of Surgeons of Edinburgh. $1995 \mathrm{Feb}:$ 40(1):25-7

7. Pluchinotta AM, Catania S. Percutaneous management of peripheral nonlactational breast abscesses. Breast Diseases 1996;9: 223-7.

8. Tan SM, Low SC. Non-operative treatment of breast abscesses. the Australian and new Zealand Journal of Surgery.1998 Jun; 68(6):423-4.

9. Singh G, Singh $G$, Singh $L R$, Singh $R$, Singh $S$, Lekhachandra KS. Management of breast abscess by repeated aspiration and antibiotics. Journal of Medical Society 2012 Sep - Dec; 26(3):189-91

10. Elagili F, Abdullah N, Fong L., Pei T. Aspiration of breast abscess under ultrasound guidance: Outcome obtained and factors affecting success. Asian Journal of Surgery 2007 Jan; 30(1):40-4.

11. Chandika AB, Gakwaya AM, Kiguli Malwadde E, Chalya PL. Ultrasound guided needle aspiration versus surgical drainage in the management of breast abscesses: A Ugandan experience. Biomed Central Research Notes 2012 Jan 6;5(12):1-7. 